\title{
The effect of low back pain and neck- shoulder stiffness on health-related quality of life: a cross-sectional population-based study
}

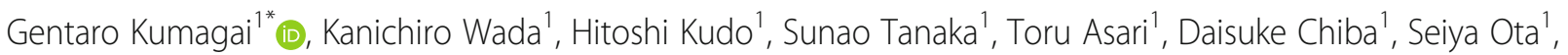
On Takeda ${ }^{1}$, Kazushige Koyama', Tetsushi Oyama', Shigeyuki Nakaji ${ }^{1}$ and Yasuyuki Ishibashi ${ }^{1}$

\begin{abstract}
Background: This cross-sectional study sought to determine the neck-shoulder stiffness/low back pain (NSS/LBP) comorbidity rate in a Japanese community population and to compare the quality of life (QOL) in individuals with comorbid NSS/LBP, asymptomatic individuals, and those with symptoms of NSS or LBP alone.

Methods: The sample included 1122 subjects (426 men; 696 women) with NSS and LBP symptoms in the previous 3 months, and were grouped according to NSS, LBP, comorbid NSS and LBP symptoms (Comorbid), or no symptoms (NP). They completed the MOS 36-Item Short-Form Health Survey (SF-36). Health QOL was evaluated by the eight domain scores and the Physical Component Summary (PCS) and Mental Component Summary (MCS) scores after adjusting for age. The primary outcome was to examine the association between NSS/LBP, NSS, or LBP and bodily pain of the eight domains of SF-36. Secondary outcome was to compare health-related QOL among the four groups.

Results: Morbidity was $45.6 \%$ for NSS and $51.9 \%$ for LBP. Comorbidity affected $23 \%$ of men and 33\% of women. Comorbid NSS/LBP, NSS, and LBP alone were independently associated with bodily pain after adjusting for potential confounders. Men who exhibited comorbidity had significantly lower MCS scores than asymptomatic men. Women who exhibited comorbidity and LBP had significantly lower MCS scores than those with no symptoms or NSS alone. Women who exhibited comorbidity had significantly lower MCS scores than those with no symptoms or LBP alone.

Conclusions: Comorbidity of the two diseases is prevalent in 23\% of the men and $33 \%$ of women in the Japanese sample. Although NSS, LBP, and comorbidity were independently associated with QOL in terms of pain, QOL was worse in individuals who exhibited comorbidity than in those without symptoms or with NSS alone.
\end{abstract}

Keywords: Neck-shoulder stiffness, Low back pain, Quality of life, Cross-sectional population-based study

\footnotetext{
* Correspondence: gen722@hirosaki-u.ac.jp

'Department of Orthopaedic Surgery, Hirosaki University Graduate School of

Medicine, 5 Zaifu-cho, Hirosaki, Aomori 036-8562, Japan

Full list of author information is available at the end of the article
}

(c) The Author(s). 2021 Open Access This article is licensed under a Creative Commons Attribution 4.0 International License, which permits use, sharing, adaptation, distribution and reproduction in any medium or format, as long as you give appropriate credit to the original author(s) and the source, provide a link to the Creative Commons licence, and indicate if changes were made. The images or other third party material in this article are included in the article's Creative Commons licence, unless indicated otherwise in a credit line to the material. If material is not included in the article's Creative Commons licence and your intended use is not permitted by statutory regulation or exceeds the permitted use, you will need to obtain permission directly from the copyright holder. To view a copy of this licence, visit http://creativecommons.org/licenses/by/4.0/ The Creative Commons Public Domain Dedication waiver (http://creativecommons.org/publicdomain/zero/1.0/) applies to the data made available in this article, unless otherwise stated in a credit line to the data. 


\section{Background}

Chronic neck pain, neck-shoulder stiffness (NSS), and low back pain (LBP) are serious health problems in the general population [1-3]. The prevalence of neck pain and LBP in the general population is $10-15 \%$ [1-4] and 15-45\% [5, 6] respectively. Moreover, the three-month prevalence of LBP or neck pain in the US is reported to be $31 \%$ (34 million people with only LBP, 9 million with neck pain, and 19 million with both LBP and neck pain) [7]. NSS, which is called "Katakori" in Japanese, is a common ailment in Japan and is characterized by myotonia, heaviness, and dull pain between the cervical and scapular region [8]. Additionally, LBP and NSS are the most frequent complaints among men and women, respectively [9]. Therefore, these symptoms contribute to the economic burden of disease [10, 11], disability [12, 13], absenteeism in the workplace [14], and diminished work capacity [11, 15]. In addition, these health issues often led to long-lasting disability [6].

While several studies have described the link between LBP or neck pain and quality of life (QOL) [16-21], they have not addressed the effect of comorbid neck and LBP symptoms on QOL. Neck pain and LBP symptoms are common to various clinical entities and can occur by themselves or along with other somatic complaints. Several studies suggest that the comorbidity of conditions like shoulder pain and LBP is associated with neck disorders and that adults with previous neck, back, or shoulder injuries are more likely to experience chronic neck pain [3]. Therefore, it is important to clarify the rate of NSS/LBP comorbidity and to determine whether comorbid NSS/LBP adversely affects QOL more than NSS or LBP alone. Accordingly, the present study sought to determine the NSS/LBP comorbidity rate in subjects who participated in a Japanese health promotion program and to compare the QOL of individuals with comorbid NSS/LBP, asymptomatic individuals, and those with symptoms of NSS or LBP alone.

\section{Methods}

\section{Participants and outline of the research}

Subjects for this cross-sectional study were recruited through the Iwaki Health Promotion Project, which provided annual health checkups to the general population in the Iwaki area of Hirosaki city, Japan over a 10-year period. Each year, the program served about 1000 people who lived in the city and were at least 19 years of age [22-24]. Our research on neck pain and LBP complaints was conducted as part of this project.

In 2014, we recruited subjects for this study from the 1167 participants of the community health program. After detailed explanation of the project was provided, participants of the community health program had the option to either take only the regular health examination or to take an extensive physical examination as part of the "Iwaki Health Promotion Project" and enroll in the study. Subjects were excluded from the study if they had a history of spine trauma or a systemic disease affecting the spine, such as rheumatoid arthritis (Fig. 1). We informed the remaining 1122 subjects (426 men and 696 women), verbally and in writing, about the study's purpose and methods, explained that their anonymity would be protected and that they could withdraw from the study at any time, and obtained their written consent for participation in the study. Informed consent, written or verbal, was obtained from all participants. Subjects completed all the questionnaires described below. This Health Promotion Project was approved by the ethics committee of the Hirosaki University Graduate School of Medicine (2019-1038).

All subjects filled out questionnaires about their medical history and lifestyle, including alcohol use, smoking, fitness habits, occupational history, family history, and QOL; subsequently, they provided information about their clinical history, specifically regarding various diseases, including neck pain or LBP. Anthropometric measurements included height, weight, body mass index (BMI), and body-fat percentage (BFP), which was assessed using a Bioelectrical Impedance Analysis (BIA) scan (MC-190, Tanita, Japan). Each subject was examined by a highly experienced orthopedist to assess the condition and range of motion of the subjects' knees, hips, elbows, neck, and lower back. All participants completed the MOS 36-Item Short-Form Health Survey (SF36) [25]. Health-related QOL was evaluated via SF-36 score, which comprises eight domains (vitality, bodily pain, general health, physical function, mental health, and social, physical, and emotional role functioning), as well as the Physical Component Summary (PCS) and Mental Component Summary (MCS) scores, after adjusting for age. The evaluation of the results was done by attributing scores to each question, which were then

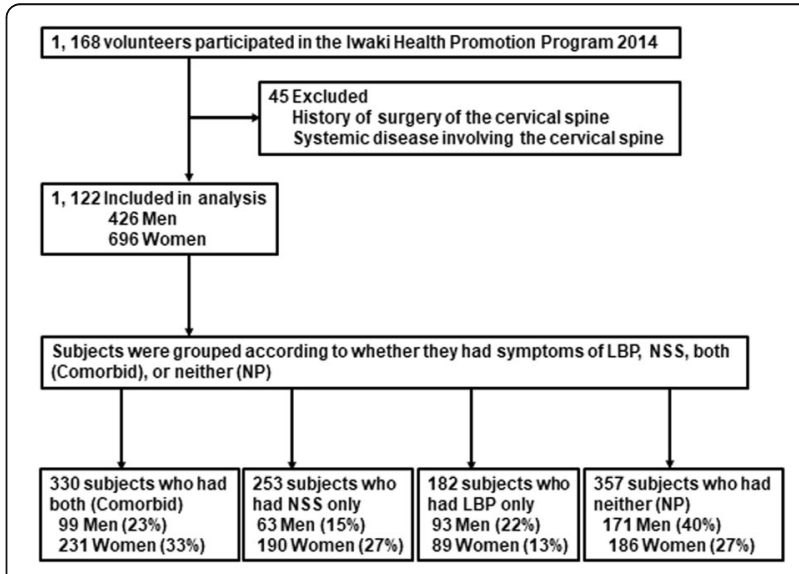

Fig. 1 Flow diagram of a cross-sectional study 
transformed into a scale ranging from 0 to 100 , where a score of 0 indicated low QOL and a score of 100 indicated a high QOL. Each dimension was analyzed separately.

\section{NSS and LBP}

Subjects filled out a questionnaire detailing whether they had experienced neck pain, NSS between the cervical and scapular regions, or LBP in the lumbar regions within the previous three months. Subjects reported the degree of NSS and LBP at the time of assessment using a visual analog scale (VAS) scored $0-100$ points $(0-100$ $\mathrm{mm}$ scale), which measured the frequency (daily, 4-5 days/week, 2-3 days/week, or less than 1/week) and prevalence of the aforementioned symptoms [23, 24]. Subjects were grouped according to whether they had symptoms of LBP, NSS, both (comorbid), or neither (NP), and health-related QOL was compared between the four groups and by gender.

\section{Statistical analysis}

Data analysis was performed using SPSS ver. $12.0 \mathrm{~J}$ software (SPSS Inc., Chicago, IL, USA). Continuous values were compared between two groups using the MannWhitney $U$ test. Categorical (or dichotomous) values were analyzed by using a chi-square test. The primary outcome was to examine the association between the incidence of comorbid or separate NSS and LBP and the continuous value of bodily pain score as a pain index of SF-36. To select potential confounders, which were defined as $p$-value $<.05$, we compared bodily pain between the existence of lifestyle and medical history using the Mann-Whitney $U$ test. Single linear regression analyses were conducted using bodily pain as the dependent variable. The independent variables measured the prevalence of NSS or LBP as separate diseases and the prevalence of NSS and LBP comorbidity. To evaluate the adjusted association, forced entry multiple linear regression analyses were conducted using bodily pain as the dependent variable, while using the prevalence of NSS and LBP separately and the prevalence of comorbidity as the independent variables, adjusted by age, gender, and BMI, which were selected from a list of potential confounders. A secondary outcome was to compare health-related QOL among the four groups by analysis of variance (ANOVA) and Tukey's post-hoc test. For all analyses, a

Table 1 Characteristics of study participants ${ }^{a}$

\begin{tabular}{|c|c|c|c|c|}
\hline & All $(n=1122)$ & Men $(n=426)$ & Women $(n=696)$ & $P$ value ${ }^{b}$ \\
\hline Age, $y^{c}$ & $54.2 \pm 15.4$ & $52.6 \pm 15.5$ & $55.3 \pm 15.3$ & $0.003^{*}$ \\
\hline $\mathrm{BMl}, \mathrm{kg} / \mathrm{m}^{2}$ & $22.7 \pm 3.4$ & $23.6 \pm 3.1$ & $22.2 \pm 3.4$ & $<0.001^{*}$ \\
\hline \multicolumn{5}{|l|}{ Highest level of education, $n(\%)$} \\
\hline Primary school & $6(0.5)$ & $3(0.7)$ & $3(0.1)$ & \\
\hline Middle school & $208(18.5)$ & $69(16.2)$ & $139(20.0)$ & \\
\hline High school & $602(53.7)$ & $249(58.5)$ & $353(50.7)$ & \\
\hline Junior college or vocational school & $214(19.1)$ & $58(13.6)$ & $156(22.4)$ & \\
\hline Graduate degree & $83(7.4)$ & $45(10.5)$ & $38(5.5)$ & \\
\hline Other & $9(8.0)$ & $2(0.5)$ & $7(1.1)$ & \\
\hline \multicolumn{5}{|l|}{ Lifestyle and medical history, $n(\%)^{d}$} \\
\hline Working & $1082(96.4)$ & $395(92.7)$ & $687(98.7)$ & $<0.001^{\#}$ \\
\hline Smokes & $129(11.5)$ & $40(9.3)$ & $89(12.8)$ & 0.474 \\
\hline Uses alcohol & $481(42.9)$ & $290(68.1)$ & $191(27.4)$ & $<0.001^{\#}$ \\
\hline Diabetes & $58(5.2)$ & $30(7)$ & $28(4)$ & $0.047^{\#}$ \\
\hline Hypertension & $282(25.1)$ & $98(23)$ & $184(26.4)$ & 0.436 \\
\hline Hyperlipidemia & $145(12.9)$ & $37(8.7)$ & $108(15.5)$ & $0.004^{\#}$ \\
\hline Depression & $5(0.4)$ & $0(0)$ & $5(0.7)$ & 0.163 \\
\hline Antidiabetic medication & $56(5.0)$ & $30(7)$ & $26(3.7)$ & $0.011^{\#}$ \\
\hline Antihypertensive medication & $277(24.7)$ & $96(22.5)$ & $181(26)$ & 0.108 \\
\hline Lipid-lowering medication & $141(12.6)$ & $36(8.5)$ & $105(15.1)$ & $0.001^{\#}$ \\
\hline Analgesic medication & $44(3.9)$ & $12(2.8)$ & $32(4.6)$ & 0.091 \\
\hline Sleeping pills medications & $37(3.3)$ & $7(1.6)$ & $30(4.3)$ & $0.015^{\#}$ \\
\hline
\end{tabular}

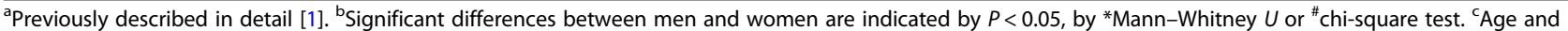
$\mathrm{BMI}$ are shown as mean \pm S.D. ${ }^{\mathrm{d}}$ The number (\%) of subjects with each characteristic 
$p$-value $<.05$ was considered statistically significant. Values of SF-36 represent means \pm standard error of the mean (s.e.m.)

\section{Results}

As shown in Table 1, the age of women was significantly higher $(55.3 \pm 15.3$ years, mean \pm SD) than that of men (52.6 \pm 15.5 years; $P=0.003)$, as was previously described in detail [24], while the mean BMI was significantly higher in men $(P<0.001)$. Significantly more men than women reported that they drank alcohol $(P<0.001)$, had diabetes $(P=0.047)$, or took diabetes medication $(P=0.011)$, whereas significantly more women reported working $(P<0.001)$, hyperlipidemia $(P=0.004)$, and use of sleeping pills $(0.015)$ and lipid-lowering medication $(P=0.001)$.

The prevalence of NSS was significantly higher in women $(60.3 \%)$ than in men $(38.0 \%, P<0.01$; Table 2$)$. NSS prompted more women $(9.2 \%)$ than men $(4.7 \%)$ to seek medical assessment, but this difference was not significant (Table 2). The prevalence of LBP was $45 \%$ in men and $46 \%$ in women; however, this difference was not significant (Table 3). LBP prompted more men (15.3\%) than women (14.7\%) to seek medical assessment, but this difference was not significant (Table 3). The prevalence of comorbid NSS/LBP was $23 \%$ in men and $33 \%$ in women (Fig. 1).

The value of bodily pain was significantly lower in subjects who had hypertension, took antihypertensive medication, analgesic medication, and sleeping pills (Table 4). We selected these medical histories as potential confounders. Single linear regression analyses showed that the prevalence of comorbidity and of LBP by itself were positively associated with bodily pain (Table 5). The prevalence of NSS separately was negatively associated with bodily pain (Table 5). Multiple linear regression analyses showed that comorbid NSS/LBP, NSS, and LBP were independently associated with bodily pain after adjusting for potential confounders (NSS alone, $\beta=-$ 0.073, 95\% CI [-2.906, - 0.293]; LBP alone, $\beta=0.143$, 95\% CI [2.126, 5.047]; comorbid, $\beta=0.243,95 \%$ CI [3.791, 6.087]; Table 5). The standardized regression coefficient for the association with bodily pain was stronger for comorbidity than for NSS and LBP separately.

Among men, MCS score was significantly lower among those who had comorbid NSS/LBP, than among those in the NP group $(P<0.001$; Fig. 2$)$. Among women, PCS score was significantly lower in the LBP group than in any of the other groups $(P<0.001$, Fig. 2$)$ and was significantly lower in the comorbid group than in the NSS group $(P<0.001$, Fig. 3). Moreover, MCS score was significantly lower in the comorbid group than in the LBP $(P=0.032)$ and NP groups $(P=0.0005$, Fig. 1$)$. Men in the comorbid group had significantly lower scores for bodily pain $(P<0.001)$, general health $(P=0.012)$, vitality $(P<0.001)$, and mental health $(P<0.001)$ than those in the NP group (Fig. 3). Among women, the scales of physical functioning, physical role functioning, bodily pain, general health, vitality, and emotional role functioning were significantly lower in the comorbid group than in the NSS or NP groups (Fig. 4). Similarly, these scores were significantly lower in the LBP group than in the NSS or NP groups, especially the physical functioning score (Fig. 4).

\section{Discussion}

We found that $23 \%$ of men and $33 \%$ of women in a Japanese sample had comorbid NSS and LBP. The prevalence of NSS and LBP separately as well as the prevalence of these diseases together were independently associated with bodily pain after adjusting for potential confounders. QOL was worse in subjects with comorbid NSS/LBP and among those with LBP separately, compared with asymptomatic subjects or those with symptoms of NSS alone.

Kumagai et al. reported a significantly higher prevalence of NSS among Japanese women $(37.3 \%, n=477)$,

Table 2 Neck-shoulder stiffness (NSS)

\begin{tabular}{|c|c|c|c|}
\hline & Men $(n=426)$ & Women $(n=696)$ & $P$ value \\
\hline NSS prevalence, $n(\%)^{\mathrm{a}}$ & $162(38.0)$ & $423(60.3)$ & $<0.001^{\#}$ \\
\hline VAS of $\mathrm{NSS}^{\mathrm{b}}$ & $36.2 \pm 23$ & $37.4 \pm 22$ & 0.558 \\
\hline \multicolumn{4}{|l|}{ NSS symptom frequency, n (\%) } \\
\hline Daily & $45(10.6)$ & $126(18.1)$ & \\
\hline 4-5 days/week & $15(3.5)$ & $59(8.5)$ & \\
\hline 2-3 days/week & $15(3.5)$ & $59(8.5)$ & \\
\hline Less than $1 /$ week & $46(10.8)$ & $105(15.1)$ & \\
\hline Symptoms medically assessed, $n(\%)$ & $20(4.7)$ & $64(9.2)$ & 0.379 \\
\hline
\end{tabular}

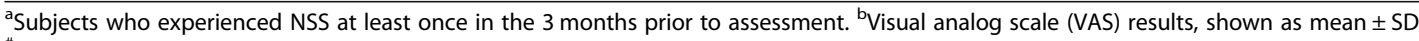

\#chi-square test 
Table 3 Low back pain (LBP)

\begin{tabular}{llll}
\hline & Men $(\boldsymbol{n}=\mathbf{4 2 6})$ & Women $(\boldsymbol{n}=\mathbf{6 9 6})$ & $\boldsymbol{P}$ value \\
\hline LBP prevalence, $n(\%)^{\mathrm{a}}$ & $192(45.1)$ & $320(46.0)$ & 0.805 \\
VAS of LBP & $31.0 \pm 21.1$ & $31.6 \pm 19.8$ & 0.530 \\
LBP symptom frequency, $n(\%)$ & & \\
$\quad$ Daily & $58(13.6)$ & $93(13.4)$ \\
4-5 days/week & $18(4.2)$ & $37(5.3)$ \\
2-3 days/week & $46(10.8)$ & $92(13.2)$ \\
Less than 1/week & $70(16.4)$ & $98(14.1)$ \\
Symptoms medically assessed, $n(\%)$ & $65(15.3)$ & $102(14.7)$ \\
\hline
\end{tabular}

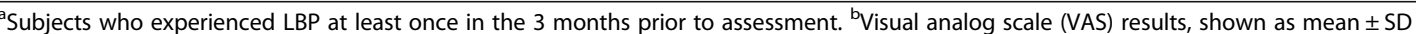

compared with men $(2.8 \% ; n=284)$ [23]. Similarly, another Japanese study reported that NSS which had a prevalence of $48.3 \%$, was more common in women than in men and was most common among individuals aged 20-50, decreasing with age thereafter [20]. Moreover, Muraki et al. reported an incidence of low back pain (LBP) of $28.3 \%$ in men and $31.2 \%$ in women (8.6 and

Table 4 Comparison of bodily pain between the prevalence of lifestyle or medical history

\begin{tabular}{|c|c|c|c|}
\hline & Existence & Bodily pain $^{a}$ & $P$ value \\
\hline \multicolumn{4}{|l|}{ Lifestyle and medical history } \\
\hline \multirow[t]{2}{*}{ Working } & Yes $(n=1077)$ & $48.7 \pm 9.1$ & 0.848 \\
\hline & No $(n=45)$ & $50.7 \pm 9.3$ & \\
\hline \multirow[t]{2}{*}{ Smokes } & Yes $(n=129)$ & $50.2 \pm 9.1$ & 0.962 \\
\hline & No $(n=993)$ & $50.8 \pm 8.6$ & \\
\hline \multirow[t]{2}{*}{ Uses alcohol } & Yes $(n=481)$ & $50.6 \pm 9.4$ & 0.492 \\
\hline & No $(n=641)$ & $50.0 \pm 9.2$ & \\
\hline \multirow[t]{2}{*}{ Diabetes } & Yes $(n=58)$ & $48.7 \pm 9.1$ & 0.336 \\
\hline & No $(n=1064)$ & $50.7 \pm 9.3$ & \\
\hline \multirow[t]{2}{*}{ Hypertension } & Yes $(n=281)$ & $48.7 \pm 9.1$ & $0.006^{*}$ \\
\hline & No $(n=841)$ & $50.7 \pm 9.3$ & \\
\hline \multirow[t]{2}{*}{ Hyperlipidemia } & Yes $(n=145)$ & $49.5 \pm 9.1$ & 0.276 \\
\hline & No $(n=977)$ & $50.4 \pm 9.2$ & \\
\hline \multirow[t]{2}{*}{ Depression } & Yes $(n=5)$ & $50.2 \pm 9.3$ & 0.509 \\
\hline & No $(n=1117)$ & $52.5 \pm 9.3$ & \\
\hline \multirow[t]{2}{*}{ Antidiabetic medication } & Yes $(n=56)$ & $48.6 \pm 10.0$ & 0.349 \\
\hline & No $(n=1066)$ & $50.3 \pm 9.2$ & \\
\hline \multirow[t]{2}{*}{ Antihypertensive medication } & Yes $(n=277)$ & $48.7 \pm 9.1$ & $0.002^{*}$ \\
\hline & No $(n=845)$ & $50.7 \pm 9.3$ & \\
\hline \multirow[t]{2}{*}{ Lipid-lowering medication } & Yes $(n=141)$ & $49.7 \pm 9.3$ & 0.546 \\
\hline & No $(n=981)$ & $50.3 \pm 9.0$ & \\
\hline \multirow[t]{2}{*}{ Analgesic medication } & Yes $(n=44)$ & $42.2 \pm 6.3$ & $<0.001^{*}$ \\
\hline & No $(n=1078)$ & $50.5 \pm 9.2$ & \\
\hline \multirow[t]{2}{*}{ Sleeping pills medications } & Yes $(n=37)$ & $45.9 \pm 9.2$ & $0.004^{*}$ \\
\hline & No $(n=1085)$ & $50.3 \pm 9.2$ & \\
\hline
\end{tabular}

${ }^{\mathrm{a}}$ Bodily pain results, shown as mean \pm SD. ${ }^{*}$ Mann-Whitney $U$
9.5\% per year, respectively) in a large-scale population of a nationwide cohort study in Japan [26]. Thus, the prevalence of NSS and LBP in our study was similar to that in previous reports. We found that the rate of NSS/ LBP comorbidity was $23 \%$ in men and $33 \%$ in women. A cross-sectional study of 21,225 twins who completed a web-based questionnaire for comorbid LBP and neckshoulder pain (NSP) showed that 13\% of women and 7\% of men had a higher prevalence [27, 28]. Genetic factors had a considerably greater influence on the occurrence of comorbid LBP and NSP [28]. Similar to previous studies, comorbid rates for women were higher than those of men. High rates of NSS and LBP comorbidity in a general population highlight the importance of considering the effect of comorbidities when studying these symptoms separately.

QOL was worse in subjects with comorbid NSS/LBP and those with LBP alone than in asymptomatic subjects or those with symptoms of NSS alone. Moreover, PCS scores, in particular, physical functioning and role physical was worse in subjects with LBP alone than other subjects in women. Many studies suggest that neck pain and LBP reduce physical activity [29] and working capacity [11], cause disability [12,13], and result in occupational absenteeism [30]. Accordingly, neck pain and LBP are negatively related to QOL [16]. However, neck pain, although less disabling than LBP [31], may still have a considerable impact on QOL. Studies in Japanese communities report that NSS is associated with pain in the upper extremities and lower QOL scores but not with pain in the lower extremities or medical complications [20], and that LBP and knee pain significantly affect individuals' QOL [21]. As expected, comorbid NSS/LBP and LBP alone were more strongly associated with QOL than NSS alone in linear regression analyses after adjusting potential confounders. The relationship between LBP or comorbid NSS/LBP and QOL, in particular bodily pain, should be considered in the context of lifestyle. In our study population, the high rate of employment $(92.7 \%$ of men and $98.7 \%$ of women) may have affected LBP but not NSS, with a consequent effect on physical-health 
Table 5 Single and multiple regression analysis relative to bodily pain ${ }^{a}$

\begin{tabular}{|c|c|c|c|c|c|}
\hline Logistic regression (Bodily pain) & & $B$ & $\beta$ & $95 \% \mathrm{Cl}$ & $P$ value \\
\hline \multirow[t]{2}{*}{ NSS alone } & Crude & -2.282 & -0.103 & -3.573 to -0.992 & 0.001 \\
\hline & Adjusted & -1.600 & -0.073 & -2.906 to -0.293 & 0.016 \\
\hline \multirow[t]{2}{*}{ LBP alone } & Crude & 4.275 & 0.170 & 2.823 to 5.728 & $<0.001$ \\
\hline & Adjusted & 3.587 & 0.143 & 2.126 to 5.047 & $<0.001$ \\
\hline \multirow[t]{2}{*}{ Comorbid } & Crude & 5.055 & 0.249 & 3.901 to 6.209 & $<0.001$ \\
\hline & Adjusted & -4.939 & 0.243 & 3.791 to 6.087 & $<0.001$ \\
\hline
\end{tabular}

B, unstandardized regression coefficient; $\beta$, standardized regression coefficient: $r^{2}$, coefficient of determination (adjusted)

${ }^{a}$ Single and forced entry multiple regression analysis was performed using bodily pain as the dependent variable and age, Gender, BMI, selected potential confounders (hypertension, antihypertensive medication, and sleeping pills medications), the prevalence of NSS, LBP alone, and comorbid NSS/LBP as independent variables

QOL in women. A longitudinal study with the same individuals may provide clues to the underlying cause of their clinical symptoms.

This study has several limitations that should be noted. First, we did not evaluate the chronicity, location, and distribution of neck pain and LBP symptoms. Particularly, chronicity should be evaluated in a future longitudinal study. Second, our study population was geographically limited to a farming village district with a high percentage of older adults. Therefore, lifestyle aspects, such as occupations and hobbies, should be considered in future studies. Third, pain in the cervical and lumbar spine can be due to a variety of causes, such as facet degeneration, lateral recess stenosis, foraminal stenosis, and herniation. Fourth, we did not examine radiographic data. Finally, the number of male subjects having neck or lumbar symptoms was relatively small. Regarding bodily pain, power analysis demonstrated that 586 male subjects would be needed to assess the statistically significant difference between NSS and NS group (G*Power, ver. 3.1.9.3; $\alpha$ error: $0.05,1-\beta$ error: 0.80 , and
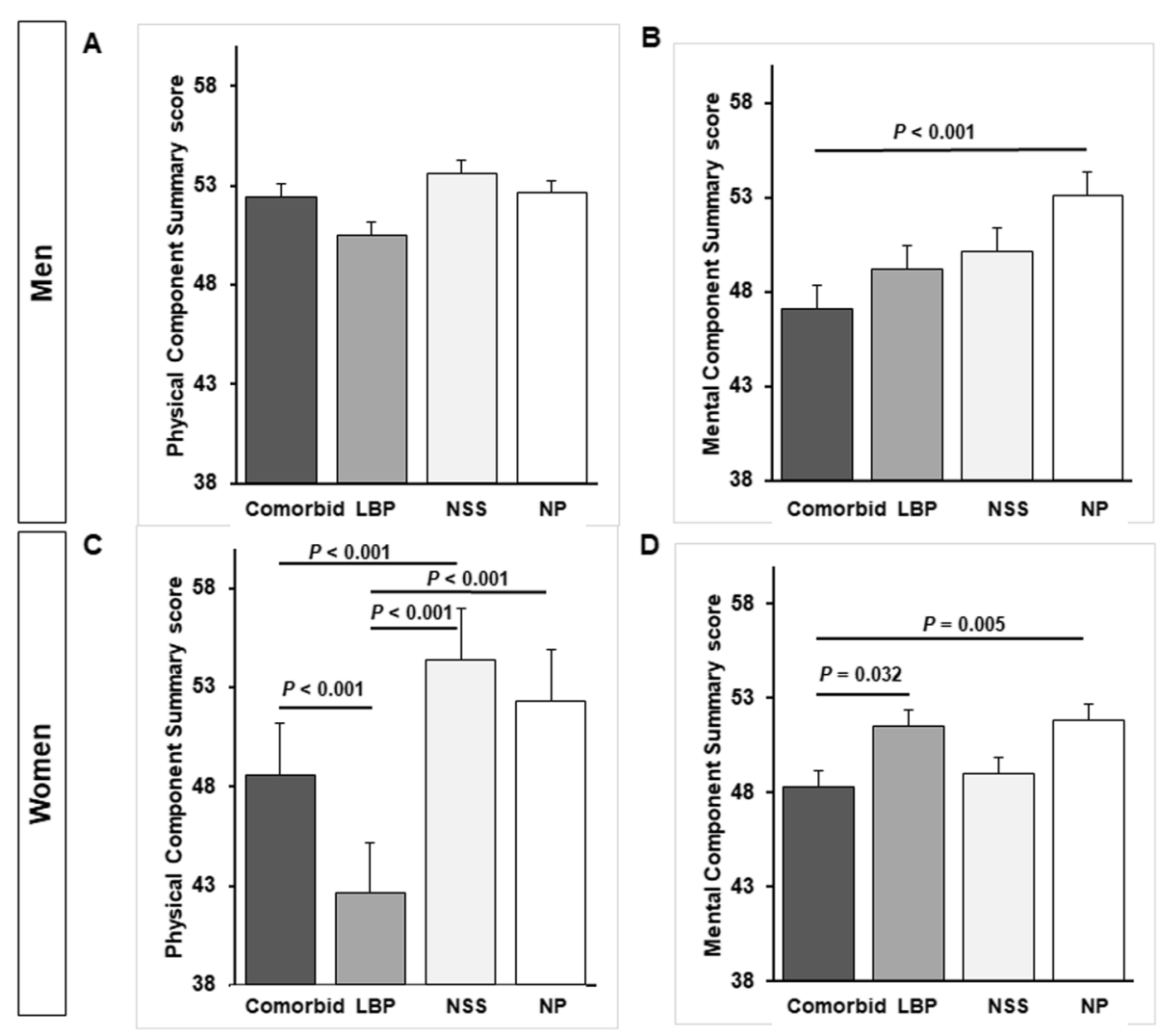

Fig. 2 Health-related QOL summaries by gender and symptom group (a, b). SF-36 PCS and MCS in men who had NP or had NSS, LBP, or comorbid NSS/LBP (c, d). Differences in PCS and MCS by symptom group in women. Values represent means \pm s.e.m. 

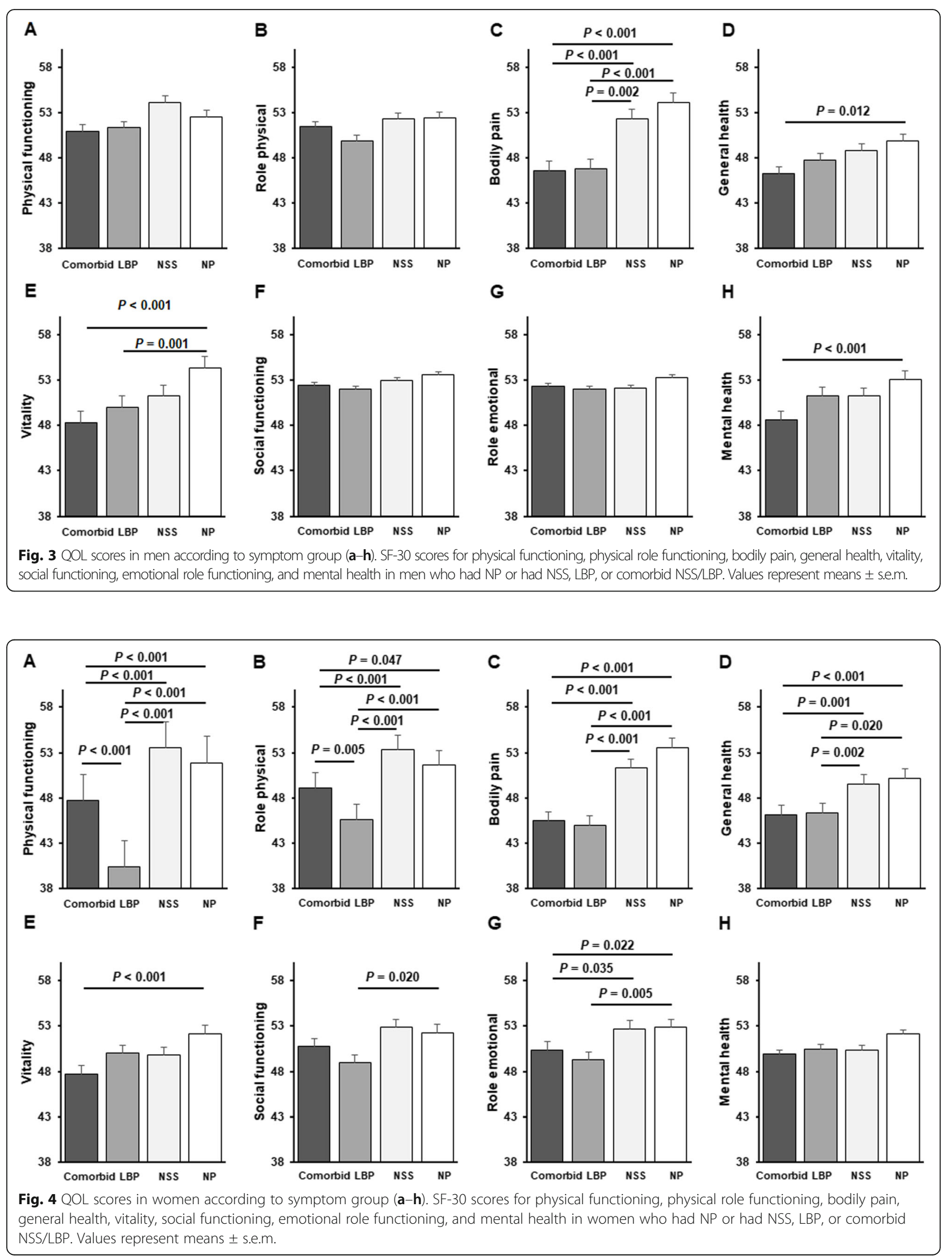
one tail). Future large-scale cohort studies could clarify the detailed pathology of neck and lumbar symptoms.

\section{Conclusions}

In summary, subjects with comorbid NSS and LBP (23\% of men and 33\% of women) had a lower QOL than asymptomatic subjects or subjects with NSS alone. Moreover, NSS/LBP comorbidity was associated with worse mental health in both men and women. NSS/LBP comorbidity also decreased physical-health QOL in women. Our current findings can be considered in differential diagnosis and in devising strategies to prevent nonspecific neck pain or LBP symptoms.

\section{Abbreviations}

NSS: Neck-shoulder stiffness; LBP: Low back pain; QOL: Quality of life weight; BMI: Body mass index; BFP: Body-fat percentage; BIA: Bioelectrical Impedance Analysis; SF-36: 36-Item Short-Form Health Survey; PCS: Physical Component Summary; MCS: Mental Component Summary; VAS: Visual analog scale; ANOVA: Among the four groups by analysis of variance

\section{Acknowledgements}

We would like to thank Editage (www.editage.com) for English language editing.

\section{Declarations}

This study was approved by the ethics committee of the Hirosaki University Graduate School of Medicine (2019-1038)

\section{Authors' contributions}

All authors contributed to the study conception and design. Material preparation, data collection, and analysis were performed by GK, KW, HK, ST, TA, DC, SO, OT, KK, and TO. The first draft of the manuscript was written by GK and all authors commented on previous versions of the manuscript. All authors read and approved the final manuscript.

\section{Funding}

This study was supported in part by a Grant-in-Aid from the Ministry of Education, Culture, Sports, Science and Technology of Japan (No. 18200044), by the Japanese Society for the Promotion of Science (No. 21500676), by the Japanese Orthopaedic Association (JOA-Subsidized Science Project Research; No. 2015-02), and by a Japanese Health Labor Sciences Research Grant.

\section{Availability of data and materials}

The datasets used and/or analysed during the current study are available from the corresponding author on reasonable request.

\section{Ethics approval and consent to participate}

We informed the remaining 1,122 subjects (426 men and 696 women), verbally and in writing, about the study's purpose and methods, explained that their anonymity would be protected and that they could withdraw from the study at any time, and obtained their written consent for participation in the study. Informed consent, written or verbal, was obtained from all participants.

\section{Competing interests}

No

\section{Author details}

${ }^{1}$ Department of Orthopaedic Surgery, Hirosaki University Graduate School of Medicine, 5 Zaifu-cho, Hirosaki, Aomori 036-8562, Japan. ²Department of Social Medicine, Hirosaki University Graduate School of Medicine, 5 Zaifu-cho, Hirosaki, Aomori 036-8562, Japan.
Received: 14 April 2020 Accepted: 10 December 2020

Published online: 05 January 2021

\section{References}

1. Brattberg G, Thorslund M, Wikman A. The prevalence of pain in a general population. The results of a postal survey in a county of Sweden. Pain. 1989; 37(2):215-22.

2. Bovim $G$, Schrader $H$, Sand T. Neck pain in the general population. Spine (Phila Pa 1976). 1994;19(12):1307-9.

3. Makela M, Heliovaara M, Sievers K, Impivaara O, Knekt $P$, Aromaa A. Prevalence, determinants, and consequences of chronic neck pain in Finland. Am J Epidemiol. 1991;134(11):1356-67.

4. Fejer R, Kyvik KO, Hartvigsen J. The prevalence of neck pain in the world population: a systematic critical review of the literature. Eur Spine J. 2006; 15(6):834-48.

5. Manchikanti L, Singh V, Datta S, Cohen SP, Hirsch JA. Comprehensive review of epidemiology, scope, and impact of spinal pain. Pain Phys. 2009;12(4): E35-70

6. Disease GBD, Injury I, Prevalence C. Global, regional, and national incidence, prevalence, and years lived with disability for 328 diseases and injuries for 195 countries, 1990-2016: a systematic analysis for the global burden of Disease study 2016. Lancet. 2017:390(10100):1211-59.

7. Strine TW, Hootman JM. US national prevalence and correlates of low back and neck pain among adults. Arthritis Rheum. 2007:57(4):656-65.

8. Okada E, Matsumoto M, Ichihara D, Chiba K, Toyama Y, Fujiwara H, Momoshima S, Nishiwaki Y, Hashimoto T, Watanabe M, et al. Development of stiff shoulder in asymptomatic volunteers during ten-year follow-up in Japan. J Back Musculoskelet Rehabil. 2010;23(2):69-75.

9. Kitahara M, Shibata M. "Katakori": A pain syndrome specific to the Japanese. Curr Pain Headache Rep. 2016;20(12):64.

10. Maetzel A, Li L. The economic burden of low back pain: a review of studies published between 1996 and 2001. Best Pract Res Clin Rheumatol. 2002; 16(1):23-30.

11. Martin BI, Deyo RA, Mirza SK, Turner JA, Comstock BA, Hollingworth W, Sullivan SD. Expenditures and health status among adults with back and neck problems. JAMA. 2008;299(6):656-64

12. Fejer R, Hartvigsen J. Neck pain and disability due to neck pain: what is the relation? Eur Spine J. 2008;17(1):80-8.

13. Niemelainen $R$, Videman T, Battie MC. Prevalence and characteristics of upper or mid-back pain in Finnish men. Spine (Phila Pa 1976). 2006;31(16):1846-9.

14. Cote P, Kristman V, Vidmar M, Van Eerd D, Hogg-Johnson S, Beaton D, Smith PM. The prevalence and incidence of work absenteeism involving neck pain: a cohort of Ontario lost-time claimants (reprinted from spine, vol 33, pg S192-S198, 2008). J Manip Physiol Ther. 2009;32(2):S219-26.

15. Linton SJ, Hellsing AL, Hallden K. A population-based study of spinal pain among 35-45-year-old individuals - Prevalence, sick leave, and health care use. Spine. 1998;23(13):1457-63.

16. Pedisic Z, Pranic S, Jurakic D. Relationship of back and neck pain with quality of life in the Croatian general population. J Manip Physiol Ther. 2013:36(5):267-75.

17. Pellise F, Balague F, Rajmil L, Cedraschi C, Aguirre M, Fontecha CG, Pasarin M, Ferrer M. Prevalence of low back pain and its effect on health-related quality of life in adolescents. Arch Pediatr Adolesc Med. 2009;163(1):65-71.

18. Ono R, Higashi T, Takahashi O, Tokuda Y, Shimbo T, Endo H, Hinohara S, Fukui T, Fukuhara S. Sex differences in the change in health-related quality of life associated with low back pain. Qual Life Res. 2012;21(10):1705-11.

19. Cote P, Cassidy JD, Carroll L. The factors associated with neck pain and its related disability in the Saskatchewan population. Spine (Phila Pa 1976). 2000;25(9):1109-17.

20. Takasawa E, Yamamoto A, Kobayashi T, Tajika T, Shitara H, Ichinose T, Mieda $T$, lizuka Y, lizuka H, Takagishi K. Characteristics of neck and shoulder pain in the Japanese general population. J Orthop Sci. 2015;20(2):403-9.

21. Muraki S, Akune T, Oka H, En-yo Y, Yoshida M, Saika A, Suzuki T, Yoshida H, Ishibashi H, Tokimura F, et al. Impact of knee and low back pain on healthrelated quality of life in Japanese women: the research on osteoarthritis against disability (ROAD). Mod Rheumatol. 2010;20(5):444-51.

22. Inoue R, Ishibashi Y, Tsuda E, Yamamoto Y, Matsuzaka M, Takahashi I, Danjo K, Umeda T, Nakaji S, Toh S. Knee osteoarthritis, knee joint pain and aging in relation to increasing serum hyaluronan level in the Japanese population. Osteoarthritis Cartilage. 2011;19(1):51-7. 
23. Kumagai $G$, Ono A, Numasawa $T$, Wada $K$, Inoue $R$, Iwasaki $H$, Iwane $K$, Matsuzaka M, Takahashi I, Umeda T, et al. Association between roentgenographic findings of the cervical spine and neck symptoms in a Japanese community population. J Orthop Sci. 2014;19(3):390-7.

24. Kumagai G, Wada K, Tanaka T, Kudo H, Asari T, Chiba D, Ota S, Nakaji S, Ishibashi Y. Associations between neck symptoms and LDL cholesterol in a cross-sectional population-based study. J Orthop Sci. 2018;23(2):277-81.

25. Ware JE Jr, Sherbourne CD. The MOS 36-item short-form health survey (SF-36). I. Conceptual framework and item selection. Med Care. 1992;30(6):473-83.

26. Muraki S, Akune T, Oka H, Ishimoto Y, Nagata K, Yoshida M, Tokimura F, Nakamura K, Kawaguchi H, Yoshimura N. Incidence and risk factors for radiographic lumbar spondylosis and lower back pain in Japanese men and women: the ROAD study. Osteoarthr Cartil. 2012;20(7):712-8.

27. Nyman T, Mulder M, lliadou A, Svartengren M, Wiktorin C. Physical workload, low back pain and neck-shoulder pain: a Swedish twin study. Occup Environ Med. 2009;66(6):395-401.

28. Nyman T, Mulder M, lliadou A, Svartengren M, Wiktorin C. High heritability for concurrent low back and neck-shoulder pain: a study of twins. Spine (Phila Pa 1976). 2011;36(22):E1469-76.

29. Leboeuf-Yde C, Fejer R, Nielsen J, Kyvik KO, Hartvigsen J. Consequences of spinal pain: do age and gender matter? A Danish cross-sectional population-based study of 34,902 individuals 20-71 years of age. BMC Musculoskelet Disord. 2011;12:39.

30. Cote P, Kristman V, Vidmar M, Van Eerd D, Hogg-Johnson S, Beaton D, Smith PM. The prevalence and incidence of work absenteeism involving neck pain: a cohort of Ontario lost-time claimants. J Manip Physiol Ther. 2009;32(2 Suppl):S219-26.

31. Hertzberg A. Prediction of cervical and low-back pain based on routine school health examinations. A nine- to twelve-year follow-up study. Scand J Prim Health Care. 1985;3(4):247-53.

\section{Publisher's Note}

Springer Nature remains neutral with regard to jurisdictional claims in published maps and institutional affiliations.

Ready to submit your research? Choose BMC and benefit from:

- fast, convenient online submission

- thorough peer review by experienced researchers in your field

- rapid publication on acceptance

- support for research data, including large and complex data types

- gold Open Access which fosters wider collaboration and increased citations

- maximum visibility for your research: over $100 \mathrm{M}$ website views per year

At $\mathrm{BMC}$, research is always in progress.

Learn more biomedcentral.com/submissions 